\title{
Research Paper: Relationship Between Social Function and Social Well-Being in Older Adults
}

\author{
Pouya Farokhnezhad Afshar ${ }^{1}$, Mahshid Foroughan ${ }^{1 *}$, Abou Ali Vedadhir ${ }^{2}$, Mahmoud Ghazi Tabatabaei
}

1. Iranian Research Center on Aging, University of Social Welfare and Rehabilitation Sciences, Tehran, Iran.

3. Department of Anthropology, Faculty of Social Sciences, University of Tehran, Tehran, Iran.

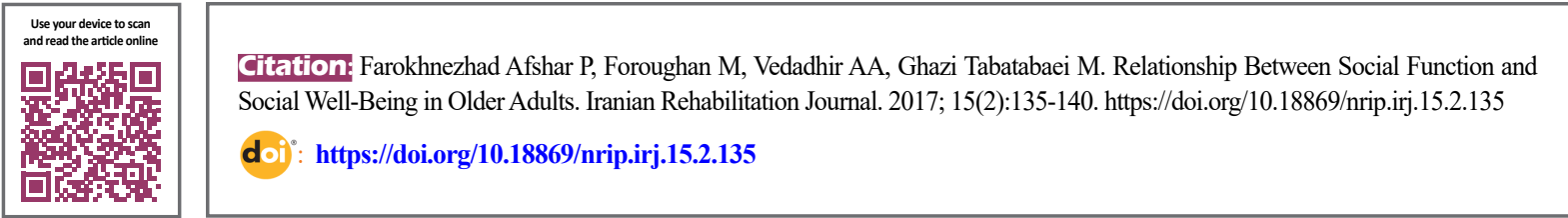

Article info:

Received: 28 Oct. 2016

Accepted: 19 Feb. 2017
Keywords:

Mental health, Social conditions, Aged, Older adults

\section{A B S T RACT}

Objectives: Health refers to the condition of perfect physical, mental and social well-being. The appropriate social well-being is the opposite of loneliness and depression. Social wellbeing is a psychosocial concept that is affected by many factors. This study determined the relationship between social function and social well-being in older adults.

Methods: This was a descriptive-analytical study that was conducted on 550 older adults in Tehran. The participants were selected by multistage cluster sampling. Data was collected using Social Well-being Scale and Social Adaptation Self-evaluation Scale. Data were analyzed using Pearson coefficient and linear regression analysis in SPSS v. 22.

Results: The mean age of participants was $66.10 \pm 6.68$ years. The female participants accounted for $41.1 \%$ of subjects. There were significant correlations between all aspects of social function (quality of activities and the quality of relationships) and social well-being dimensions $(\mathrm{P}<0.01)$. The quality of activities had significant positive effects on all aspects of social well-being $(\mathrm{P}<0.01)$, and the quality of relationships also had significant effects on different aspects of social well-being, except on social coherence $(\mathrm{P}=\mathrm{n} . \mathrm{s})$.

Discussion: The findings showed that the social function affects social well-being. So individuals with higher social functioning also have higher social well-being and mental health.

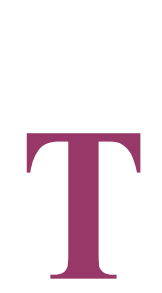

\section{Introduction}

he world population is aging rapidly due to reduced mortality and fertility. The aging population is estimated to be more than a billion people by 2025 [1]. Old age can be considered as a transition period both in terms of physical and mental conditions and so- cial status [2]. The old people may face social changes such as mandatory retirement, role crisis, and social isolation [3]. Therefore, it is important to pay attention to the social needs of this population.

Health is one of the essential needs of older adults. According to the World Health Organization (1948), health is a "state of complete physical, mental and social well- 
being and not merely the absence of disease or infirmity" [4]. Generally, well-being is defined with respect to two main hedonic and eudemonic paradigms. In hedonic perspective, the purpose of life is happiness, having mental and physical satisfaction, and being away from pain and suffering; this is synonymous with emotional well-being [5]. However, in eudemonic perspective, well-being means to acquire good traits and explain the good state of a person; it is synonymous with psychological wellbeing [6]. However, some researchers believe that wellbeing should be composed of different areas of both hedonic and eudemonic paradigms because these concepts are mutually dependent and represent a wider and more accurate scheme of well-being [5].

Physical and mental well-being have been investigated more than social well-being; in other words, social wellbeing has been neglected to a certain degree [7]. Generally, social well-being is evaluated by health or diseasecentered models at three levels: individual, interpersonal and societal (Table 1) [8]. Keyes defined social well-being at the individual level as "one's assessment of his or her conditions and functioning in the society." It is based on the eudemonic paradigm and health-centered model and can also be considered as a part of positive mental health [9].

According to the disengagement theory, older people usually tend to disengage from their environment and this disengagement leads to their well-being [10]. However, the activity theory states that active life has a direct effect on the well-being of older adults [11]. The activities of older adults have been studied in many ways, including activities of daily living and social functioning [12]. It is known that social function is an important aspect of life for the older adults [13]. Social function explains a person's overall function in many aspects of daily living activities, including independent life, employment, social interaction, and leisure time [14]. It has become evident that social function affects an individual's health, which in turn affects his/ her social relations [15]. On the other hand, a decline in social function is associated with reduced mental health, and people with depression suffer from some degree of decline in social function [16].

$\mathrm{Pu}$ et al., showed that prefrontal cortex activity in older adults is associated with their social function, and frontal lobe deficits can lead to functional changes such as apathy, changes in interpersonal relationships, and irritability [17]. Kong et al., also found that social well-being is related to the activities of some regions of the brain, such as bilateral temporal gyrus, right anterior cingulate cortex, and prefrontal cortex. As these regions are involved in social cognition $[18,19]$, these two concepts may be interconnected. Regarding the relationship between social function with life satisfaction and active aging, this study determined the relationship between different aspects of social function and social well-being in older adults in Tehran.

\section{Methods}

This descriptive-analytical study is a part of a larger study [20]. The ethics committee of the University of Social Well-being and Rehabilitation Sciences confirmed this study (Ref.,IR.USWR.REC.1394.1).

\section{Participants}

The study population comprised 550 persons aged over 60 years in Tehran who were selected via multistage cluster sampling from the neighborhoods house in Tehran. The inclusion criteria were giving informed consent to participate in the study and having normal cognitive status according to the Mini-Cog test results [21, 22].

\section{Measures}

We used the Social Well-being Scale (SWS) and Social Adaptation Self-evaluation Scale (SASS) to collect data. The SWS has 33 items in five dimensions [9]. Responses are rated from strongly disagree [1] to strongly agree [7] (4 - No idea). The overall reliability of the scale was obtained by internal consistency ( $\alpha=0.94)$, and Cronbach's alpha for each dimension was calculated including social integration $(\alpha=0.89)$, social acceptance $(\alpha=0.87)$, social contribution $(\alpha=0.83)$, social actualization $(\alpha=0.90)$, and social coherence $(\alpha=0.86)$ [9].

Bosc et al., developed a 20-item SASS to investigate the social function in relation to work, communication, hobbies, satisfaction with one's function, and ability to manage the environment. The SASS is a good scale to assess social function [16, 23, 24]. Each question is scored from 0 to 3 with the minimum and maximum scores ranging from 0 to 60 ; the high scores showed a good social function. The Persian version of this scale was validated by Farokhnezhad Afshar et al., (2017) in Iran, who showed that the SASS consists of two subscales: the quality of activities and the quality of relationships [25]. Cronbach's $\alpha$ for the quality of activities and relationship sub-scales was 0.96 and 0.95 , respectively. The overall Cronbach's $\alpha$ was 0.97 . Finally, data were analyzed using IBM SPSS statistics (V.22), Pearson correlation coefficient and multiple regression analysis tests. 


\section{Results}

The participants were $58.9 \%$ male and $41.1 \%$ female $(\mathrm{n}=550)$. The mean age of participants was $66.10 \pm 6.68$ years. The participants had different marital status: married (78.4\%), widowed (12\%), single (6.4\%), and divorced $(3.3 \%)$. They were illiterate $(14.5 \%)$ or had primary education $(49.8 \%)$, high school $(26.5 \%)$, and college education $(9.1 \%)$. The employment status was as follows: employed (26.7\%), unemployed (5.8\%), retired $(37.5 \%)$, housewife $(22.9 \%)$, and disabled (7.1\%).There was a negative correlation between age and social function $(\mathrm{r}=-0.25)$ and social well-being $(\mathrm{r}=-0.19)(\mathrm{P}<0.01)$. The social function was not different between old men and old women $(\mathrm{P}=0.07)$, but their social well-being was significantly different (Table 2). A significant and positive correlation was found between social function dimensions and social well-being dimensions (Table 3).

The regression analysis showed that the quality of activities $(\beta=0.33)$ and the quality of relationships $(\beta=0.26)$ explained the social integration variance. The social acceptance was predicted by the quality of activities $(\beta=0.34)$ and the quality of relationships $(\beta=0.10)$. The quality of activities $(\beta=0.34)$ and the quality of relations $(\beta=0.30)$ also predicted the variance of social contribution. Social actualization was affected by the quality of activities $(\beta=0.23)$ and the quality of relations $(\beta=0.24)$. Significant predictors of social coherence only included the quality of activities $(\beta=0.38)$ (Table 4$)$.

\section{Discussion}

The results of this study showed that there is no significant difference between social function in older men and women, but men had better conditions in social well-being. There was a positive correlation between social function and social well-being dimensions in older adults such that social well-being increased with the increase in social function. The social function and social well-being decreased with increasing age. The regression analysis revealed that the quality of activities was a significant predictor of the five dimensions of social well-being. The quality of the relationships had no significant effect on social coherence.

The social function decreases in people with depression and vice versa, and it is at a high level in healthy subjects [26]. On the other hand, high social well-being

Table 1. Social well-being concepts classification

\begin{tabular}{cccc}
\hline & Individual & Interpersonal & Societal \\
Health-centered model & Social well-being & Social support & Social capital \\
Disease-centered model & Alienation & Violence & Poverty rate
\end{tabular}

Table 2. Differences between elder men and women in SWS and SASS

\begin{tabular}{|c|c|c|}
\hline & SASS (X $\pm S D)$ & SW (X士SD) \\
\hline Male & $37.79 \pm 11.27$ & $140.65 \pm 37.25$ \\
\hline Female & $38.50 \pm 10.96$ & $137.91 \pm 32.45$ \\
\hline P & 0.07 & 0.03 \\
\hline
\end{tabular}

SASS: Social Adaptation Self-evaluation Scale; SW: Social Well-being

Iranian Rehabilitation Journal

Table 3. Correlation coefficients among social function and social well-being

\begin{tabular}{|c|c|c|c|c|c|c|}
\hline & & $\begin{array}{c}\text { Social } \\
\text { Integration }\end{array}$ & $\begin{array}{c}\text { Social } \\
\text { Acceptance }\end{array}$ & $\begin{array}{c}\text { Social } \\
\text { Contribution }\end{array}$ & $\begin{array}{c}\text { Social } \\
\text { Actualization }\end{array}$ & $\begin{array}{c}\text { Social } \\
\text { Coherence }\end{array}$ \\
\hline Activities quality & $r$ & $0.53^{* *}$ & $0.41^{* *}$ & $0.56^{* *}$ & $0.41^{* *}$ & $0.40^{* *}$ \\
\hline $\begin{array}{l}\text { The quality of the } \\
\text { relationships }\end{array}$ & $r$ & $0.52^{* *}$ & $0.36^{* *}$ & $0.55^{* *}$ & $0.42^{* *}$ & $0.31^{* *}$ \\
\hline
\end{tabular}

** $\mathrm{P}<0.001$

Iranian Rehabilitation Journal

r: Correlation coefficient 
Table 4. Multiple regression analysis social function and social well-being

\begin{tabular}{|c|c|c|c|c|c|c|c|c|c|c|c|c|c|c|c|}
\hline & \multicolumn{3}{|c|}{$\begin{array}{c}\text { Social } \\
\text { Integration }\end{array}$} & \multicolumn{3}{|c|}{$\begin{array}{c}\text { Social } \\
\text { Acceptance }\end{array}$} & \multicolumn{3}{|c|}{$\begin{array}{c}\text { Social } \\
\text { Contribution }\end{array}$} & \multicolumn{3}{|c|}{$\begin{array}{c}\text { Social } \\
\text { Actualization }\end{array}$} & \multicolumn{3}{|c|}{$\begin{array}{c}\text { Social } \\
\text { Coherence }\end{array}$} \\
\hline & $\beta$ & $\mathbf{T}$ & $\mathbf{P}$ & $\beta$ & $\mathbf{T}$ & $\mathbf{P}$ & $\beta$ & $\mathbf{T}$ & $\mathbf{P}$ & $\beta$ & $\mathbf{T}$ & $\mathbf{P}$ & $\beta$ & $\mathbf{T}$ & $\mathbf{P}$ \\
\hline Activities quality & 0.33 & 5.91 & $<0.001$ & 0.34 & 5.57 & $<0.001$ & 0.34 & 6.21 & $<0.001$ & 0.23 & 3.83 & $<0.001$ & 0.38 & 6.23 & $<0.001$ \\
\hline $\begin{array}{l}\text { The quality of the } \\
\text { relationships }\end{array}$ & 0.26 & 4.70 & $<0.001$ & 0.10 & 1.60 & 0.11 & 0.30 & 5.46 & $<0.001$ & 0.24 & 4.02 & $<0.001$ & 0.02 & 0.29 & 0.77 \\
\hline Adj. $R^{2}$ & \multicolumn{3}{|c|}{0.31} & \multicolumn{3}{|c|}{0.17} & \multicolumn{3}{|c|}{0.35} & \multicolumn{3}{|c|}{0.19} & \multicolumn{3}{|c|}{0.15} \\
\hline $\mathrm{F}$ & \multicolumn{3}{|c|}{123.67} & \multicolumn{3}{|c|}{58.57} & \multicolumn{3}{|c|}{149.58} & \multicolumn{3}{|c|}{67.66} & \multicolumn{3}{|c|}{51.59} \\
\hline$P$ & \multicolumn{3}{|c|}{$<0.001$} & \multicolumn{3}{|c|}{$<0.001$} & \multicolumn{3}{|c|}{$<0.001$} & \multicolumn{3}{|c|}{$<0.001$} & \multicolumn{3}{|c|}{$<0.001$} \\
\hline
\end{tabular}

$\beta$ : Standardized coefficients; $R^{2}$ : Coefficient of determination; P: P-value, F: F-test

represents positive mental health. The social function and social well-being are associated with positive mental health, so we can deduce their correlation. Social integration refers to self-evaluation of the person's quality of his/her relationships with others [9]. The relationships are affected by the social function [27].

So, the older adults' quality of relationships is directly associated with social integration. According to the Durkheim Theory, social integration has a significant effect on health, in particular, mental health. It suggests that the community members are dependent on the function of each other, and this strengthens the social integration [28, 29]. Acceptance is an individual's interpretation of the community and reflects his or her confidence in others [9]. According to the disengagement theory, the social role and communications of older people reduce with age and retirement [11], and based on the social reconstruction theory, the roles of older people are taken from them, and instead, false negative beliefs regarding their roles are installed in their self-concept [2].

So, it has an unfavorable effect on the individual's interpretation of their community and also, this is reflected in his or her relations and communications with others. The social contribution has been defined as a self-evaluation of his or her social value [6]. The activity theory states that the older people tend to continue their activities; however, the type of their activities may change in the aging period [10]. Continuity of activities and interest to communicate are prerequisites for social contribution [30]; thus, they could have important effects on the quality of activities and the quality of relationships on social contribution. The social actualization is having a hopeful attitude towards the future of society [8]. The studies have shown people who have a poor social func- tion are disappointed and have a negative view of the future $[23,31]$.

On the other hand, according to Ericsson's theory, the older adults review their past and pay less attention to the future [2]. Social coherence refers to the ability of the individual to understand the meaning and relatedness of the events surrounding them [32]. The quality of the relationships did not affect social coherence; this could be because older adults experienced negative changes in their social environment. This may lower their social coherence and, in turn, weaken its correlation with the quality of their relations $[8,33]$. Social function can be of effective factors in social well-being and positive mental health of older adults [34].

The psycho-social concepts are complex and have mutual relationships with each other. So, it is important to find important psycho-social factors that may have effects on the well-being of older adults. This study found that the quality of activities and the quality of relationships have important effects on older adults' social wellbeing. The results of this study showed that the older adults' quality of activities has a positive effect on social well-being. However, the quality of the relationships was effective only in the social integration, social contribution, and social actualization dimensions. Generally, it can be said that the older adults who have a high social function also have higher social well-being and positive mental health. Therefore, it is recommended to encourage the older adults to have more appropriate social activities and relationships.

\section{Acknowledgments}

This study was supported by grant No. 9352 in University of Social Wellfare and Rehabilitation Sciences. We thank all those who helped us in this study. 


\section{Conflict of Interest}

The authors declared no conflicts of interest.

\section{References}

[1] Afshar PF, Asgari P, Shiri M, Bahramnezhad F. A review of the Iran's elderly status according to the census records. Galen Medical Journal. 2016; 5(1):1-6.

[2] Rice FP. Human development: A life-span approach. New Jersey: Prentice Hall; 2001.

[3] Gilmour H. Social participation and the health and wellbeing of Canadian seniors. Health Reports. 2012; 23(4):23-32. PMID: 23356042

[4] Larson JS. The World Health Organization's definition of health: Social versus spiritual health. Social Indicators Research. 1996; 38(2):181-92. doi: 10.1007/bf00300458

[5] Ryan RM, Deci EL. On happiness and human potentials: A review of research on hedonic and eudaimonic well-being. Annual Review of Psychology. 2001; 52(1):141-66. doi: 10.1146/annurev.psych.52.1.141

[6] Joshanloo M. Mental well-being in Iran: The importance of comprehensive well-being in understanding the linkages of personality and values. In: Keyes CLM, editor. Mental wellbeing: International contributions to the study of positive mental health. Dordrecht: Springer; 2013.

[7] Abachizadeh K, Tayefi B, Nasehi AA, Memaryan N, Rassouli M, Omidnia S, et al. Development of a scale for measuring social health of Iranians living in three big cities. Medical Journal of the Islamic Republic of Iran. 2014; 28:1-9. PMID: 25250247

[8] Keyes CL, Shapiro AD. Social well-being in the United States: A descriptive epidemiology. In: Brim OG, Ryff C, Kessler R, editors. How healthy are we? A national study of wellbeing at midlife. Chicago: University of Chicago; 2004

[9] Keyes CLM. Social well-being. Social Psychology Quarterly. 1998; 61(2):121-40. doi: 10.2307/2787065

[10] Settersten RA, Angel JL. Handbook of sociology of aging. Berlin: Springer; 2011.

[11] Hooyman NR, Kiyak HA. Social gerontology: A multidisciplinary perspective. London: Pearson Education; 2008

[12] McDowell I. Measuring health: A guide to rating scales and questionnaires. $3^{\text {rd }}$ edition. New York: Oxford University Press; 2006.

[13] Bond J, Corner L. Quality of life and older people. New York: McGraw-Hill Education; 2004

[14] Wang Y, Yeh YH, Tsang SM, Liu WH, Shi HS, Li Z, et al. Social functioning in Chinese College Students with and without Schizotypal personality traits: An exploratory study of the Chinese version of the first episode social functioning scale. PloS one. 2013; 8(5):61115. doi: 10.1371/journal.pone.0061115
[15] Mauk KL. Gerontological nursing: Competencies for care. Sudbury: Jones \& Bartlett Pub; 2006.

[16] Bosc M. Assessment of social functioning in depression Comprehensive Psychiatry. 2000; 41(1):63-9. doi: 10.1016/ s0010-440x(00)90133-0

[17] Pu S, Nakagome K, Yamada T, Yokoyama K, Matsumura $\mathrm{H}$, Mitani $\mathrm{H}$, et al. Association between social functioning and prefrontal hemodynamic responses in elderly adults. Behavioural Brain Research. 2014; 272:32-9. doi: 10.1016/j bbr.2014.06.052

[18] Kong F, Hu S, Xue S, Song Y, Liu J. Extraversion mediates the relationship between structural variations in the dorsolateral prefrontal cortex and social well-being. Neuroimage. 2015; 105:269-75. doi: 10.1016/j.neuroimage.2014.10.062

[19] Kong F, Xue S, Wang X. Amplitude of low frequency fluctuations during resting state predicts social well-being. Biological Psychology. 2016; 118:161-8. doi: 10.1016/j.biopsycho.2016.05.012

[20] Afshar PF, Foroughan M, Vedadhir A, Tabatabaei MG The effects of place attachment on social well-being in older adults. Educational Gerontology. 2016; 43(1):45-51. doi: 10.1080/03601277.2016.1260910

[21] Borson S, Scanlan J, Brush M, Vitaliano P, Dokmak A The Mini-Cog: A cognitive'vital signs' measure for dementia screening in multi-lingual elderly. International Journal of Geriatric Psychiatry. 2000; 15(11):1021-7. doi 10.1002/1099-1166(200011)15:11<1021::aid-gps234>3.0.co;2-6

[22] Sadeghipour Roodsari M, Akbari Kamrani A, Foroughan M, Mohammadi F, Karimloo M. [Validity and reliability of the Clock Drawing Test in older people (Persian)]. Iranian Journal of Ageing. 2013; 8(2):48-53.

[23] Bosc M, Dubini A, Polin V. Development and validation of a social functioning scale, the Social Adaptation Self-evaluation Scale. European Neuropsychopharmacology. 1997; 7(1):57-70. doi: 10.1016/s0924-977x(97)00420-3

[24] Weissman MM, Olfson M, Gameroff MJ, Feder A, Fuentes $\mathrm{M}$. A comparison of three scales for assessing social functioning in primary care. American Journal of Psychiatry. 2001; 158(3):460-6. doi: 10.1176/appi.ajp.158.3.460

[25] Farokhnezhad Afshar P, Foroughan M, Vedadhir A, Ghazi Tabatabaie M. Psychometric properties of the persian version of Social Adaptation Self-evaluation Scale in communitydwelling older adults. Clinical Interventions in Aging. 2017; 12:579-84. doi: 10.2147/cia.s129407

[26] Tse WS, Bond AJ. Psychometric analysis of the Chinese version of Social Adaptation Self-evaluation Scale (C-SASS) Psychiatry Research. 2007; 153(3):277-81.

[27] McNamara P, Stavitsky K, Durso R, Harris E. The impact of clinical and cognitive variables on social functioning in Parkinson's disease: Patient versus examiner estimates. Parkinson's Disease. 2010; 2010:1-6. doi: 10.4061/2010/263083

[28] Berkman LF, Glass T. Social integration, social networks, social support, and health. New York: Oxford University Press; 2000.

[29] Ritzer G. Contemporary sociological theory and its classical roots: The basics. New York: McGraw-Hill Education; 2009. 
[30] Klandermans B. Mobilization and participation: Socialpsychological expansions of resource mobilization theory. American Sociological Review. 1984; 49(5):583-600. doi: $10.2307 / 2095417$

[31] Hirsch JK, Sirois FM, Lyness JM. Functional impairment and depressive symptoms in older adults: Mitigating effects of hope. British Journal of Health Psychology. 2011; 16(4):74460. doi: $10.1111 / \mathrm{j} .2044-8287.2010 .02012 . x$

[32] Joshanloo M, Rostami R, Nosratabadi M. [Examining the factor structure of the Keyes' comprehensive scale of well-being (Persian)]. Journal of Iranian Psychologists. 2006; 3(9):3551.

[33] Khalili F, Sam SH, Shariferad G, Hassanzadeh A, Kazemi M. [The relationship between perceived social support and social health of elderly (Persian)]. Health System Research. 2012; 7(6):1217.

[34] Rashedi V, Gharib M, Yazdani AA. Social participation and mental health among older adults in Iran. Iranian Rehabilitation Journal. 2014; 12(1):9-13. 